\title{
Metasurface Superstrate Beam Steering Antenna with AMC for 5G/WiMAX/WLAN Applications
}

\author{
Akhilesh Verma \\ Delhi Technological University \\ Ravi Kumar Arya ( $\nabla$ raviarya@gmail.com ) \\ National Institute of Technology Delhi \\ Srinivasa Nallanthighal Raghava \\ Delhi Technological University
}

\section{Research Article}

Keywords: Monopole, Beam steering, Metasurface superstrate, 5G.

Posted Date: December 8th, 2021

DOI: https://doi.org/10.21203/rs.3.rs-695261/v1

License: (c) (1) This work is licensed under a Creative Commons Attribution 4.0 International License. Read Full License 


\section{Abstract}

A beam-steering antenna based on non-uniform metasurface superstrate and AMC, operating at $3.5 \mathrm{GHz}$, is presented. The antenna can steer the beam along $\theta=-18^{\circ}$ and $18^{\circ}$ with the superstrate and along $\theta=0^{\circ}$ in the absence of the superstrate with almost zero scan loss. Antenna structure consists of a top layer of non-uniform metasurface superstrate made of a $20 \times 20$ grid of electrically-small square-shaped metallic pixels while the bottom part consists of AMC with a grid of $5 \times 5$ pixels. The radiating element, $C P W$-fed monopole antenna, is placed between $\mathrm{AMC}$ and superstrate. The fabricated prototype shows desired beam steering in directions of $\theta=-18^{\circ}, 0^{\circ}$, and $18^{\circ}$ while maintaining uniform realized gain of $5.5 \mathrm{~dB}$ and matches well with simulations.

\section{Introduction}

Fifth generation (5G) is the recent wireless technology that is the next step towards the evolution of cellular communication systems [1], [2]. In 5G, the beam steering capability of the antenna plays the main role for efficient coverage to all users [3]. Beam steering is the solution to today's network problems such as call drops, multipath fading in crowded areas [4], [5]. Optical beam scanning for short range communication is presented in [6], which achieved $10^{\circ}$ beam scanning. Beam scanning is achieved with the help of waffle and waffle iron waveguides. Many beam steering methods have been discussed and reported in [7], which shows one of the methods of beam steering is Birefringent Prisms. However, this method is limited as it requires prism thickness of more than $8 \mathrm{~cm}$ which may create the problem of beam walkof [8], [9] when the beam needs to be steered by $20^{\circ}$. The precise beam steering is obtained using 1D optical phased array on silicon-on-insulator which achieves $2.3^{\circ}$ at wavelength of $1550 \mathrm{~nm}$ and $14.1^{\circ}$ steering. The design is, however, limited due to its high cost and complication in designing with low beam scanning [10]. The reconfigurable partial reflecting surface (PRS) structure was deployed to achieve beam steering from $-15^{\circ}$ to $15^{\circ}$ as reported in [11]. Besides this, the microstrip leaky wave antenna has achieved frequency scanning capability with two tapered slots in the leaky section and reduction of side lobe level is obtained by Yagi elements [12]. Also, $0^{\circ}$ to $40^{\circ}$ beam scanning is reported in [13] with the help of an electronically controlled microstrip antenna, and changing the capacitance value. The tilted beam at $\pm 15^{\circ}$ is observed in [14], by combining parasitic elements with inserted capacitances. The parasitic phased array antenna with varactors and tuning capacitance which provides continuous scanning of \pm $15^{\circ}$ is reported in [15]. A reconfigurable microstrip Yagi antenna is presented in [16] and beam scanning from $-40^{\circ}$ to $+40^{\circ}$ in $\mathrm{H}$-plane is achieved by two hexagonal slotted tunable parasitic elements with the gain of $3.36 \mathrm{dBi}$. The beam steering of $-30^{\circ}, 0^{\circ},+30^{\circ}$ is reported in [17], which used a grid of $5 \times 5$ electrically-small rectangular-shaped metallic pixels on the upper layer of the parasitic layer which are connected by switches. However, $360^{\circ}$ beam steering is presented in [18] by combining electronically steerable parasitic array radiator (ESPAR) antenna and the water antenna, but it makes the design complex and cannot be easily designed. In [19], phase varying metamaterial is used for compact steerable directive antenna which achieves $a \pm 20^{\circ}$ steered beam. Furthermore, different beam steering methods have been reported in [20]. 
In next sections, we provide a step-by-step approach to design the proposed antenna. Sec. II starts with the design of a radiating element, CPW-fed monopole antenna. Once, radiating element is designed, the design of AMC and superstrate is discussed. Next, in Sec. III, various parameters of composite antenna with $\mathrm{AMC}$ and superstrate are studied so that change in antenna behavior due to change in these parameters can be quantified. This section also discusses desired radiation behaviors of the proposed antenna. Finally, Sec. IV concludes the work with concluding remarks.

\section{li. Geometry Of The Proposed Antenna}

\section{(a) Design of CPW fed monopole antenna}

The radiating element, CPW fed monopole antenna, geometry is shown in Fig. 1. Due to simple design and single side design on substrate, this radiating element is selected for this research. For design, the length of the monopole antenna is denoted as $I$, and width is denoted by $W$. The monopole antenna is fed through $50 \Omega$ SMA connector. The antenna is fabricated on FR4 $\left(\epsilon_{r}=4.4, \tan \delta=0.02\right)$ substrate with a thickness of $1.6 \mathrm{~mm}$. The other dimensions of the antenna are given as:

$L_{p}=35, W_{p}=22, l=16.7, m=9.1, g=0.3, l_{1}=10$ (alldimensionsareinmm).

\section{(b) Design of AMC for CPW fed monopole antenna}

The center frequency of AMC operation is chosen to be $3.5 \mathrm{GHz}$. A unit cell of periodicity $10 \mathrm{~mm} \times 10 \mathrm{~mm}$ is used for AMC design. Square-shaped metallic patches of side ' $a$ ' are printed at the center of the unit cell on FR4 substrate as shown in Fig. 2 (a). The substrate has thickness, $h_{1}=3.2 \mathrm{~mm}$ with permittivity of 4.4 , and loss tangent of 0.02 . For analysis of $A M C$, the periodic boundary condition (PBC) $[19,20,21,22,23]$ is used. It facilitates quick results instead of simulating the large structure of $A M C$. By using PBC, shown in Fig. 2(b), the reflection phase is calculated by simulation with the help of Floquet port excitation.

In order to ascertain that the AMC is indeed working on desired $3.5 \mathrm{GHz}$, unit cell simulation with variable side of the square pixel, $a$, is run and an attempt is made so that the reflection phase is $0^{\circ}$ at desired 3.5 GHz. From Fig. 2(c), we can see that when the side of the pixel, $a$, is $9.6 \mathrm{~mm}$, the reflection phase is $0^{\circ}$. Henceforth, we will use AMC made of unit cells with $a=9.6 \mathrm{~mm}$ to use with the monopole antenna discussed earlier.

\section{(c) Design of composite CPW fed monopole antenna with AMC and superstrate}


In the previous section, we designed AMC. Next, we place AMC underneath the antenna substrate as shown in Fig. 3 so that the AMC enhances the radiation in forward direction, i.e., along vertically up direction. It can be seen from Fig. 3 that the grid of $5 \times 5 \mathrm{AMC}$ unit cells is placed under the monopole antenna. It is well known that the superstrate can be used to increase the gain of the antenna $[24,25,26$, 27]. Mostly, the superstrate used for enhancing the design is either in the form of uniform pixels or pixels whose size changes radially out from the center of the superstrate. In such applications, the primary role of superstrate is to work in Fabry-Perot configuration and enhance the gain of the antenna element. In this research, we have a dual purpose of the superstrate. On one hand we want to modify the gain of the antenna and on the other, we want to steer the beam emanating from the antenna in the desired direction. This type of beam steering is very important for upcoming $5 \mathrm{G}$ systems. Figure 4 (a) shows the geometry of the proposed superstrate which comprises of metallic patches of different size from $a_{1}$ to $a_{20}$. The dimensions of the proposed superstrate are given in Table 1.

In order to steer the beam in direction away from the broadside, there should be phase variation for waves emanating from different locations of the superstrate. This phase-varying behavior is provided by a nonuniform metasurface printed on the dielectric substrate acting as a superstrate. For this purpose, the size of the unit cells of the superstrate increases monotonically from one edge to another of the superstrate as shown in Fig. 4 (a). This way, the superstrate will help to steer the beam in an offbroadside direction. If this superstrate sends the beam in $+\theta$, rotating the superstrate by $180^{\circ}$, taking the $z$-axis for rotation, will help to send the beam in the $-\theta$ direction. In order to send the beam in broadside direction, the superstrate is removed. To ease the rotation, the interchange of the superstrate may be accomplished by a mechanical solution. In this way, this design can be said to be reconfigurable. However, the speed of beam steering will depend upon how quickly the mechanical motor can help to rotate or remove the superstrate.

Figure 4 (b) shows the layered structure of the proposed CPW fed monopole antenna with AMC and superstrate with different views. The fabricated prototype of the proposed antenna is shown in Fig. 5.

Table 1

Patch dimensions (in $\mathrm{mm}$ ) used in metasurface superstrate.

\begin{tabular}{|llllllllll|}
\hline $\mathrm{a}_{1}$ & $\mathrm{a}_{\mathbf{2}}$ & $\mathrm{a}_{\mathbf{3}}$ & $\mathbf{a}_{\mathbf{4}}$ & $\mathrm{a}_{\mathbf{5}}$ & $\mathrm{a}_{6}$ & $\mathrm{a}_{\mathbf{7}}$ & $\mathrm{a}_{\mathbf{8}}$ & $\mathrm{a}_{9}$ & $\mathrm{a}_{10}$ \\
\hline 0.125 & 0.25 & 0.375 & 0.5 & 0.625 & 0.75 & 0.875 & 1 & 1.125 & 1.25 \\
$\mathrm{a}_{11}$ & $\mathrm{a}_{12}$ & $\mathrm{a}_{13}$ & $\mathrm{a}_{14}$ & $\mathrm{a}_{15}$ & $\mathrm{a}_{16}$ & $\mathrm{a}_{17}$ & $\mathrm{a}_{18}$ & $\mathrm{a}_{19}$ & $\mathrm{a}_{20}$ \\
1.375 & 1.5 & 1.625 & 1.75 & 1.875 & 2 & 2.125 & 2.25 & 2.375 & 2.5 \\
\hline
\end{tabular}

\section{lii. Results And Discussion}


All the simulations in this work are conducted using Ansys HFSS, full wave simulator. The simulated Sparameter comparison of the monopole antenna, monopole antenna with $\mathrm{AMC}$, monopole antenna with AMC and superstrate is shown in Fig. 6.

The comparison of the realized gain for monopole antenna with AMC and superstrate is shown in Fig. 7. It can be observed that there is $3.84 \mathrm{dBi}$ increment in gain after applying $\mathrm{AMC}$ on the monopole antenna. Furthermore, when the superstrate is applied, the gain of the antenna is $5.5 \mathrm{dBi}$ at $3.5 \mathrm{GHz}$.

\section{A. Parametric analysis of the antenna}

The proposed antenna is fed by CPW as shown in Fig. 1. The parametric studies of the dimensions of the monopole antenna, gap between antenna and superstrate has been carried out to achieve good impedance matching and desired frequency band.

\section{i) Length of monopole antenna, I}

The length of the monopole antenna, $I$, is varied from $20 \mathrm{~mm}$ to $30 \mathrm{~mm}$ with the step size of $5 \mathrm{~mm}$. As shown in Fig. 8 (a) the reflection coefficient $S_{11}$ is lower than - $10 \mathrm{~dB}$ for desired frequency bands. It can also be observed that the $S_{11}$ resonance moves to lower frequency as the length of the monopole increases.

\section{ii) Gap between the antenna and superstrate}

The gap between antenna and superstrate is varied from $4.2 \mathrm{~mm}$ to $10.2 \mathrm{~mm}$ with the step size of $3 \mathrm{~mm}$. It can be seen from Fig. 8. (b) that there is hardly any effect of varying the gap on the antenna performance. In this way, the antenna will give almost the same results even if the gap changes due to slight mishandling of the antenna.

\section{B. Near field analysis}

In order to get insights of working of the superstrate, near field behavior is very helpful [25]. Far field pattern being the Fourier transform of the near-field pattern, can give better understanding of how the superstrate is changing the near field that will eventually change the far field characteristics. To accomplish it, a vertical plane in the center of the antenna is placed on which the dominant component of the near field is studied. In our case, $E_{x}$ is the dominant electric field as the monopole is aligned along the $x$-axis. In Fig. 9 and Fig. 10, $E_{x}$ magnitude and phase behavior in absence and presence of the superstrate are shown. It is evident from Fig. 9 (a) and Fig. 10 (a) that the placement of the superstrate confines the fields and hence shows slightly higher field magnitude in case of the superstrate. It is also evident from Fig. 9 (b) and Fig. 10 (b) that due to placement of the superstrate, the direction of equi-phase front changes. The phase front is changed towards left, signifying that the outward radiation is expected towards left side when the superstrate is placed. From these figures, it is easy to understand that the absence or presence of the superstrate decides the beam steering direction. 
After getting the desired radiation properties, the prototype of the antenna is fabricated as shown in Fig. 5. The proposed antenna is tested using R \& S ZNB40 vector network analyzer and anechoic chamber for its properties.

\section{S-parameter measurement}

The simulated and measured S-parameters of the antenna are shown in Fig. 11. For acceptable performance, the proposed antenna needs to provide good reflection coefficients, |S11|, in the desired frequency band. From Fig. 11, it is evident that the fabricated antenna has $|\mathrm{S} 11|<-10 \mathrm{~dB}$ over the frequency band of 3.1-3.7 GHz. The simulated and measured S-parameters are in good agreement. The fabricated antenna has wide impedance bandwidth for 5G/WiMAX/WLAN applications.

\section{Radiation pattern of the proposed antenna}

Figure 12 shows the radiation pattern of the proposed antenna for $\varphi=0^{\circ}$ cut. The non-uniform superstrate was designed to steer the beam in $\theta= \pm 18^{\circ}$. The superstrate needs to be mechanically rotated or removed depending upon the desired steering beam direction. While, currently, we manually did the operation of mechanically placing and removing the superstrate but the superstrate can be moved by mechanical motor to automate this operation. This type of mechanical movement of a superstrate is simple and can be easily accomplished by mechanical motors.

It can be seen from Fig. 12 that the beam scans in $\pm 18^{\circ}$ and $0^{\circ}$ in elevation directions in presence of superstrate and in absence respectively. It is also interesting to note that the antenna does not show sidelobes in this plane. The realized gains at these steered angles are $5.5 \mathrm{~dB}$ signifying that the antenna shows almost zero scan loss for $\pm 18^{\circ}$ scanning angles.

The proposed antenna radiation patterns (co- and cross-polarization) are measured in an anechoic chamber at $3.5 \mathrm{GHz}$ as shown in Figs. 13 and 14. In these figures, co-polarization is shown by red lines and cross-polarization by black lines. It is evident from Figs. 13 and 14, that the antenna has very low cross-polarization components. The simulated and measured results are also in good agreement.

\section{E. Realized gain}

Figure 15 shows the simulated and measured gain of the antenna with and without superstrate. It is observed that the gain of the antenna in both cases is $5.5 \mathrm{dBi}$ at $3.5 \mathrm{GHz}$. The simulated and measured values are also in good agreement. 


\section{Comparison table}

In Table 2, all existing designs are compared with the current work. It is evident from Table 2 that the proposed antenna gives a good beam steering with compact design.

Table 2

Comparison of present work with the previously published antennas

\begin{tabular}{|c|c|c|c|c|c|}
\hline Ref & Antenna type & $\operatorname{Size}\left(\lambda_{0}^{3}\right)$ & $\begin{array}{l}\text { Frequency } \\
\text { band } \\
(\mathrm{GHz})\end{array}$ & $\begin{array}{l}\text { Realized } \\
\text { gain } \\
\text { (dBi) }\end{array}$ & $\begin{array}{l}\text { Beam } \\
\text { scanning } \\
\text { (Degrees) }\end{array}$ \\
\hline [11] & $\begin{array}{l}\text { Phased array and } \\
\text { reconfigurable PRS } \\
\text { structure }\end{array}$ & $3.1 \times 3.1 \times 0.55$ & 5.5 to 5.7 & 12 & $\pm 15^{\circ}$ \\
\hline [14] & $\begin{array}{l}\text { Parasite patches and } \\
\text { lumped capacitances }\end{array}$ & $1.56 \times 0.63 \times 0.013$ & 2.45 & $5-8$ & $\pm 15^{o}$ \\
\hline [15] & $\begin{array}{l}\text { Parasitic phased array } \\
\text { antennas }\end{array}$ & $0.30 \times 0.78 \times 0.005$ & 1 & 7.4 & $\pm 15^{o}$ \\
\hline [16] & Tunable parasitic & $0.49 \times 0.49 \times 0.0013$ & $2.43-2.47$ & 3.36 & $\pm 40^{\circ}$ \\
\hline $\begin{array}{l}\text { This } \\
\text { Work }\end{array}$ & $\begin{array}{l}\text { Metasurface monopole } \\
\text { Antenna }\end{array}$ & $0.58 \times 0.58 \times 0.16$ & $3.1-3.7$ & 5.53 & $\pm 18^{\circ}$ \\
\hline
\end{tabular}

\section{Iv. Conclusion}

A beam-steering antenna based on non-uniform metasurface superstrate and AMC with CPW-fed monopole antenna as radiating element operating at $3.5 \mathrm{GHz}(3.1-3.7 \mathrm{GHz})$ was presented. The antenna is able to steer beams in directions of $-18^{\circ}, 0^{\circ}$ and $-18^{\circ}$ in elevation while maintaining uniform gain of $5.5 \mathrm{dBi}$. The antenna is compact, has a good front to back ratio and low sideline levels. The antenna due to these qualities is an ideal candidate for 5G, WiMAX and WLAN applications.

\section{Declarations}

Funding: The authors did not receive support from any organization for the submitted work

Conflicts of interest/Competing interests: The Authors declares that there is no conflict of interest'.

Availability of data and material (data transparency): Data sharing not applicable -no new data generated, or the article describes entirely theoretical research data sharing not applicable to this article as no datasets were generated or analysed during the current study.

Code availability (software application or custom code): No codes are used in this manuscript. 
Authors' contributions: All authors contributed to the study conception and design. Material preparation, data collection and analysis were performed by Akhilesh Verma, Ravi Kumar Arya and Srinivasa Nallanthighal Raghava. The first draft of the manuscript was written by Akhilesh Verma and all authors commented on previous versions of the manuscript. All authors read and approved the final manuscript.

\section{References}

1. Yu, B., Yang, K. and Yang, G., 2017. A novel $28 \mathrm{GHz}$ beam steering array for $5 \mathrm{G}$ mobile device with metallic casing application. IEEE Transactions on Antennas and Propagation, 66(1), pp.462-466.

2. Zhang, S., Syrytsin, I. and Pedersen, G.F., 2018. Compact beam-steerable antenna array with two passive parasitic elements for $5 \mathrm{G}$ mobile terminals at $28 \mathrm{GHz}$. IEEE Transactions on Antennas and Propagation, 66(10), pp.5193-5203.

3. Shah, A.S.A., Abd Rahman, N.H., Ali, M.T., Fauzi, N.F. and Ab Aziz, A.A., 2016, December. Beam scanning of phased array antenna using phase modification method for satellite application. In 2016 IEEE Asia-Pacific Conference on Applied Electromagnetics (APACE) (pp. 291-295). IEEE.

4. Serhsouh, I., Himdi, M., Lebbar, H. and Vettikalladi, H., 2020. Reconfigurable SIW antenna for fixed frequency beam scanning and $5 \mathrm{G}$ applications. IEEE Access, 8, pp.60084-60089.

5. Wu, L., Farrall, A.J. and Young, P.R., 2015. Substrate integrated waveguide switched beam antenna. IEEE Transactions on Antennas and Propagation, 63(5), pp.2301-2305.

6. Arai, H., 2019, November. High gain optical beam scanning antenna and its measurement. In 2019 IEEE Asia-Pacific Conference on Applied Electromagnetics (APACE) (pp. 1-3). IEEE.

7. McManamon, P.F., Bos, P.J., Escuti, M.J., Heikenfeld, J., Serati, S., Xie, H. and Watson, E.A., 2009. A review of phased array steering for narrow-band electrooptical systems. Proceedings of the IEEE, 97(6), pp.1078-1096.

8. U. Schmidt and W. Hust, BOptical deflection system including an alternating sequence of birefringent prisms and polarizers, [ U.S. Patent 3572 895, Dec. 1986.

9. M. A. Karim, D. Cook, and P. F. McManamon, BDigital beam steering system using modules of ferro electric liquid crystal and Wollaston prism,[ in Tech. Dig. 1988 Annu. Meeting Opt. Soc. Amer., Santa Clara, CA, Oct. 1988, p. 118.

10. Van Acoleyen, K., Bogaerts, W., Jágerská, J., Le Thomas, N., Houdré, R. and Baets, R., 2009. Off-chip beam steering with a one-dimensional optical phased array on silicon-on-insulator. Optics letters, 34(9), pp.1477-1479.

11. Ji, L.Y., Guo, Y.J., Qin, P.Y., Gong, S.X. and Mittra, R., 2015. A reconfigurable partially reflective surface (PRS) antenna for beam steering. IEEE Transactions on Antennas and Propagation, 63(6), pp.23872395.

12. Tanoli, S.A.K., Khan, M.I., Fraz, Q., Yang, X. and Shah, S.A., 2018. A compact beam-scanning leakywave antenna with improved performance. IEEE Antennas and Wireless Propagation Letters, 17(5), pp.825-828. 
13. Symeonidou, A. and Siakavara, K., 2013. A novel microstrip antenna array with metamaterial-based electronic beam steering at $2.4 \mathrm{GHz}$. Progress In Electromagnetics Research, 38, pp.27-42.

14. Dias, M.H.C., Freitas, V. and Vuong, T.P., 2015. Low cost electronic beam tilting of microstrip antennas by the use of tunable parasites. Microwave and Optical Technology Letters, 57(11), pp.2710-2713.

15. Luther, J.J., Ebadi, S. and Gong, X., 2012. A microstrip patch electronically steerable parasitic array radiator (ESPAR) antenna with reactance-tuned coupling and maintained resonance. IEEE Transactions on Antennas and Propagation, 60(4), pp.1803-1813.

16. Khairnar, V.V., Kadam, B.V., Ramesha, C.K. and Gudino, L.J., 2018. A reconfigurable parasitic antenna with continuous beam scanning capability in H-plane. AEU-International Journal of Electronics and Communications, 88, pp.78-86.

17. Li, Z., H. Mopidevi, O. Ğ. U. Z. Kaynar, and B. A. Cetiner. "Beam-steering antenna based on parasitic layer." Electronics Letters 48, no. 2 (2012): 59-60.

18. Xing, L., Zhu, J., Xu, Q., Yan, D. and Zhao, Y., 2019. A circular beam-steering antenna with parasitic water reflectors. IEEE Antennas and Wireless Propagation Letters, 18(10), pp.2140-2144.

19. Ourir, A., S. N. Burokur, and A. De Lustrac. "Phase-varying metamaterial for compact steerable directive antennas." Electronics letters 43, no. 9 (2007): 493-494.

20. Uchendu, I. and Kelly, J.R., 2016. Survey of beam steering techniques available for millimeter wave applications. Progress In Electromagnetics Research B, 68, pp.35-54.

21. Ravi Kumar Arya, Shiyu Zhang, Shaileshachandra Pandey, Ashwani Kumar, Y. Vardaxoglou, William Whittow and Raj Mittra, "Meta-Atoms and Artificially Engineered Materials for Antenna Applications," in Developments in Antenna Analysis and Design: Volume 1 edited by Raj Mittra, pp. 351-405, IET, UK, 2018 DOI: 10.1049/SBEW543F_ch10

22. Akhilesh Verma, Ravi Kumar Arya, Rajarshi Bhattacharya, Srinivasa Nallanthighal Raghava, "Compact PIFA Antenna with High Gain and Low SAR using AMC for WLAN/C-band/5G Applications " IETE Journal of Research, 2021 doi:10.1080/03772063.2021.1945958

23. R. K. Arya, C. Pelletti and R. Mittra, "Numerically Efficient Technique for Metamaterial Modeling," Progress In Electromagnetics Research, Vol. 140, pp. 263-276, 2013 DOI: 10.2528/PIER13051313

24. Anil Kumar Yerrola, Ravi Kumar Arya, Maifuz Ali, and Lakhindar Murmu, "Non-Omnidirectional Monopole using Holographic Surfaces with Reduced SLL." URSI GASS 2021, Rome, Italy, 28 August - 4 September, 2021.

25. Li, Y., Mittra, R., Zeng, B., Lu, G., Li, Z., Liu, J., ... \& Chang, D. C. (2012). Directivity enhancement of fabry-perot antenna by using a stepped-dielectric slab superstrate. Microwave and Optical Technology Letters, 54(3), 711-715.

26. Mittra, Raj, Yanfei Li, and Kyungho Yoo. "A comparative study of directivity enhancement of microstrip patch antennas using three different superstrates." Microwave and Optical technology letters 52.2 (2010): 327-331.

27. Ji, L.-Y., Guo, Y. J., Qin, P.-Y., Gong, S.-X., \& Mittra, R. (2015). A Reconfigurable Partially Reflective Surface (PRS) Antenna for Beam Steering. IEEE Transactions on Antennas and Propagation, 63(6), 
2387-2395.

28. Schneider, John B. "Understanding the finite-difference time-domain method." School of electrical engineering and computer science Washington State University 28 (2010).

\section{Figures}

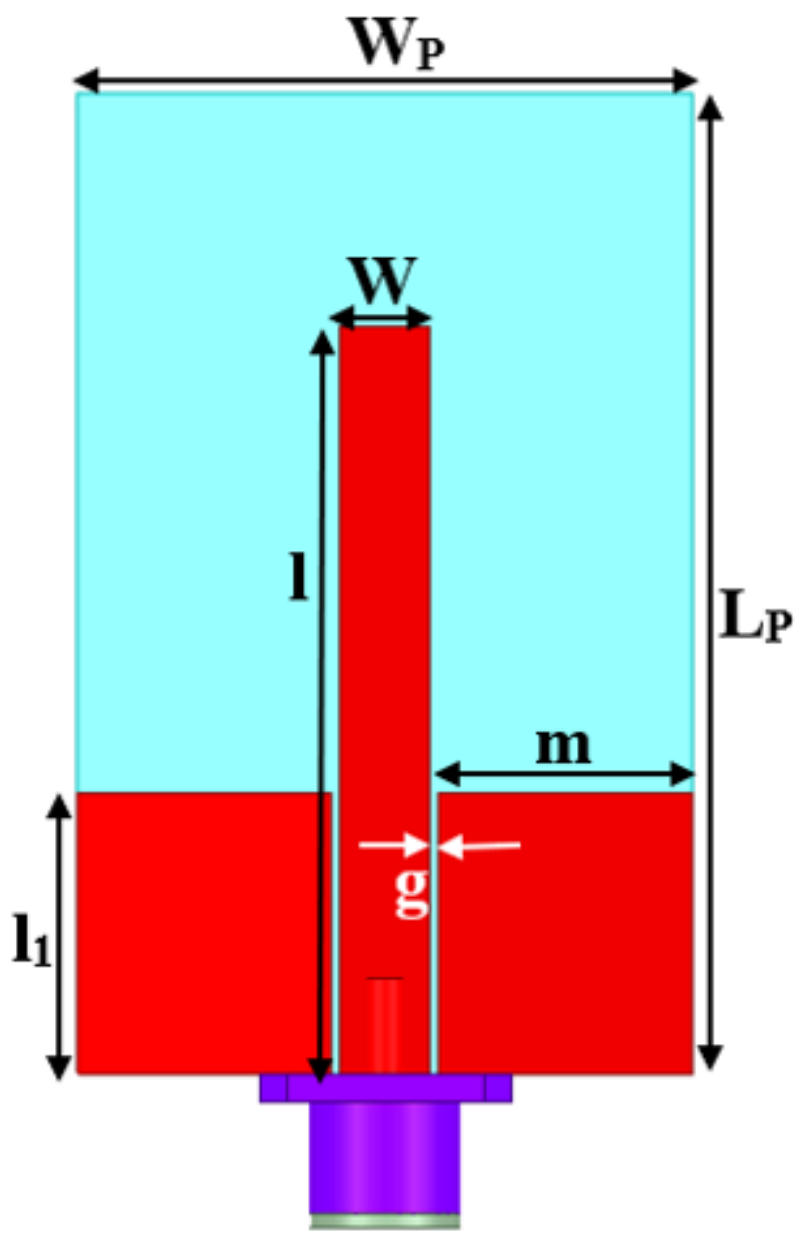

Figure 1

Proposed CPW fed monopole antenna. 


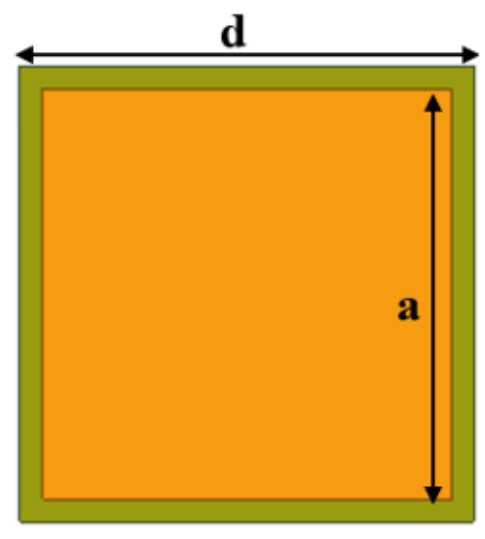

(a)

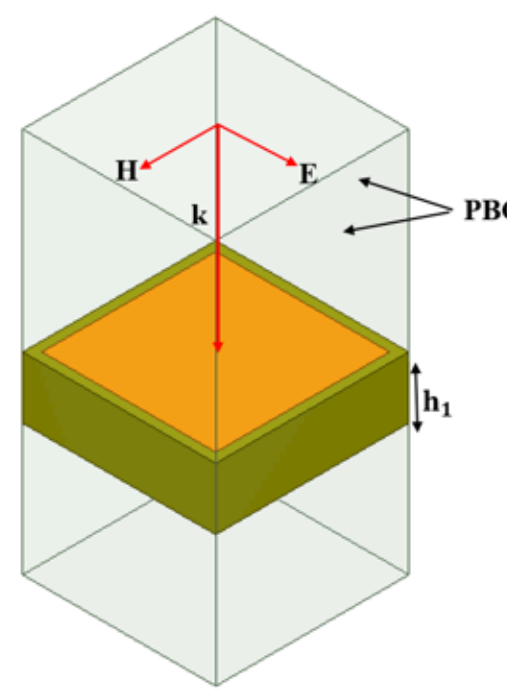

(b)

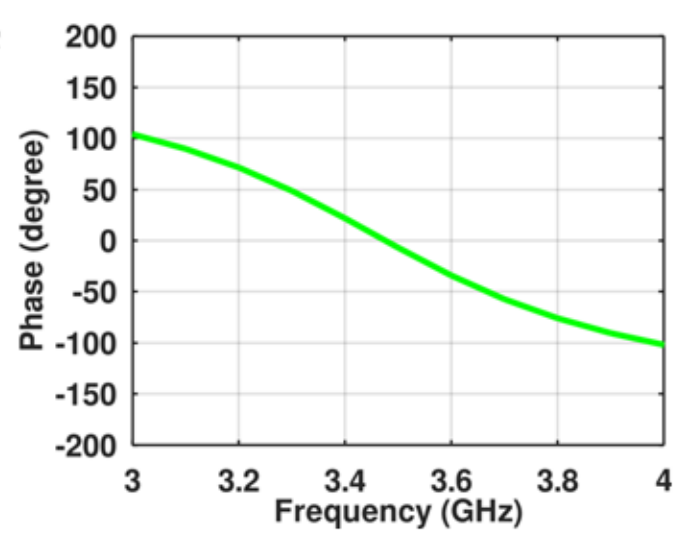

(c)

Figure 2

AMC design for proposed CPW fed monopole antenna, (a) top view of AMC, (b) isometric view of AMC, (c) reflection phase behavior of the AMC.

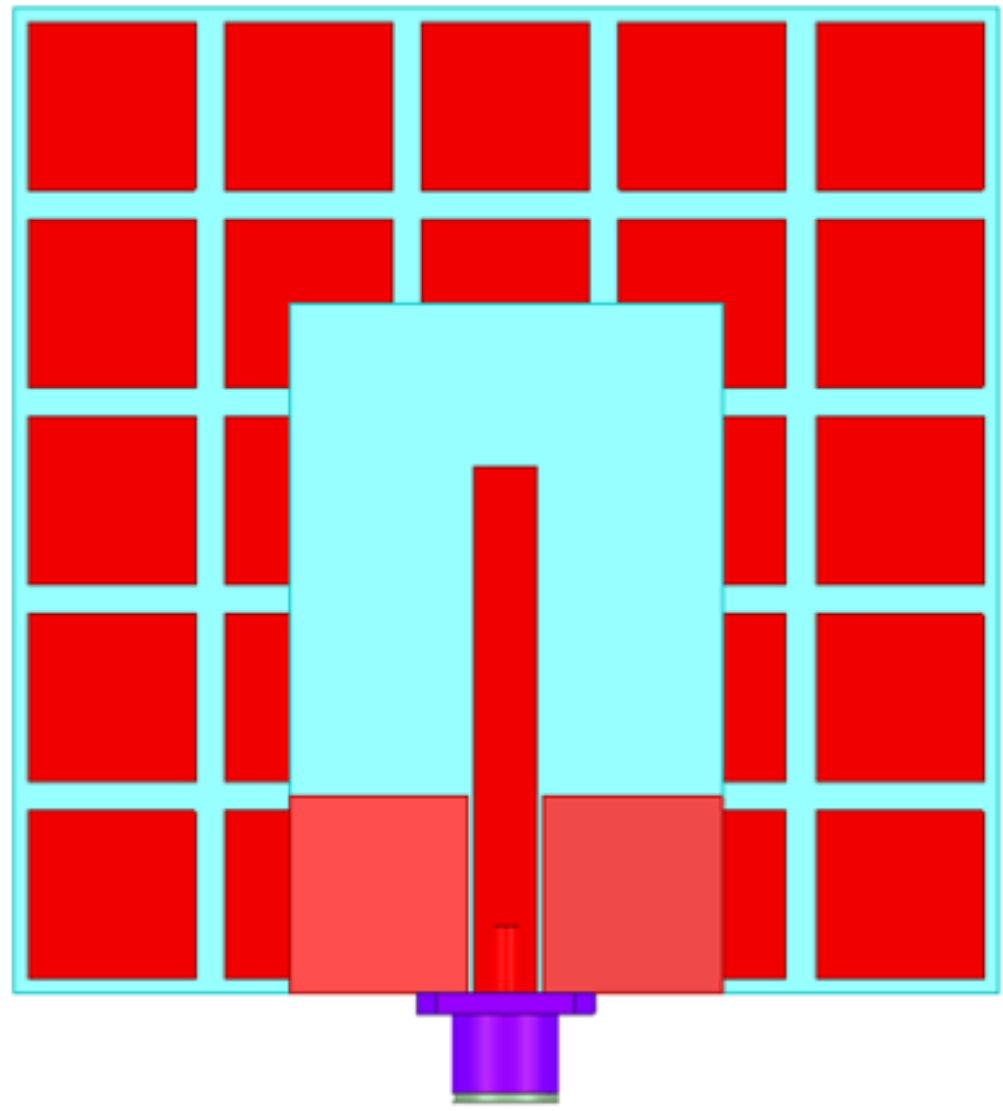

Figure 3 
CPW fed monopole antenna with AMC.

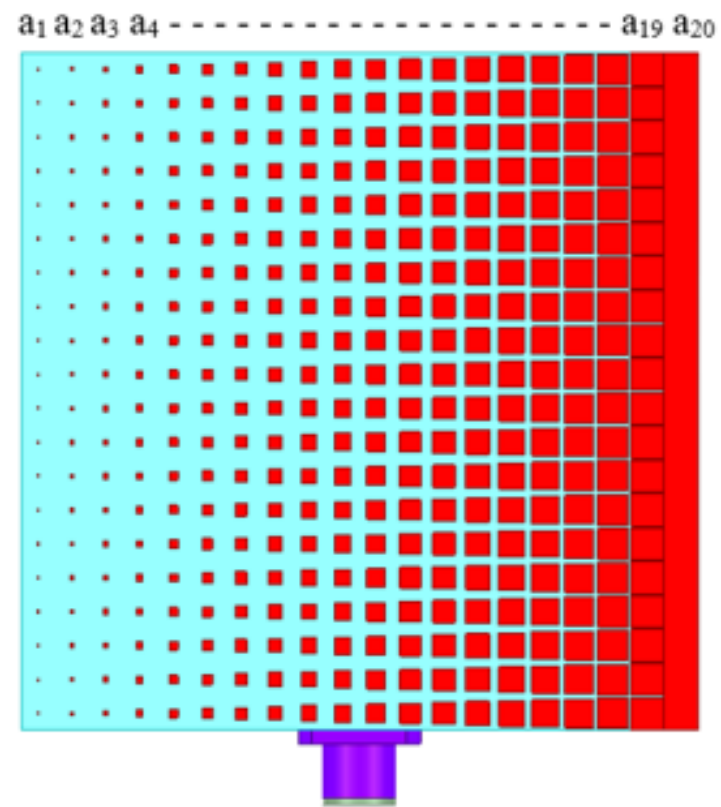

(a)

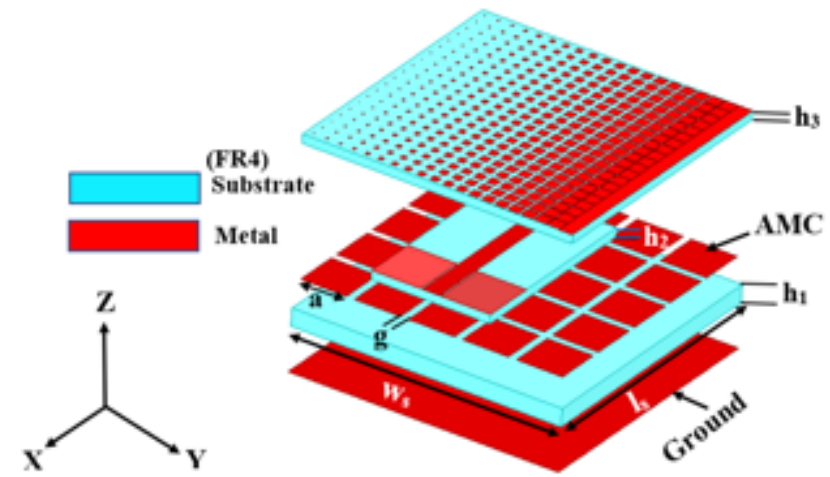

(b)

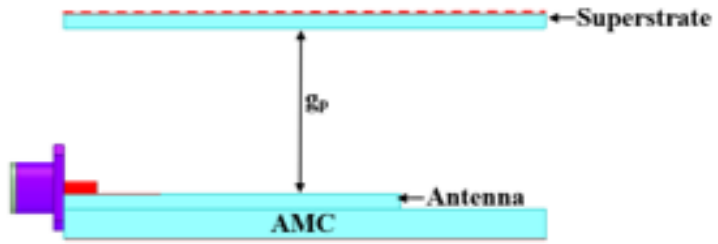

(c)

\section{Figure 4}

CPW fed monopole antenna with AMC and superstrate. (a) layered structure, (b) side view. $\left(\mathrm{I} \_\mathrm{s}=50, \mathrm{~W} \_\mathrm{s}=50, \mathrm{~h} \_1=3.2, \mathrm{~h} \_2=1.6, \mathrm{~h} \_3=1.6, \mathrm{~g}=0.17, \mathrm{~g} \_\mathrm{p}=7.2\right.$ (all dimensions in $\mathrm{mm}$ ). 


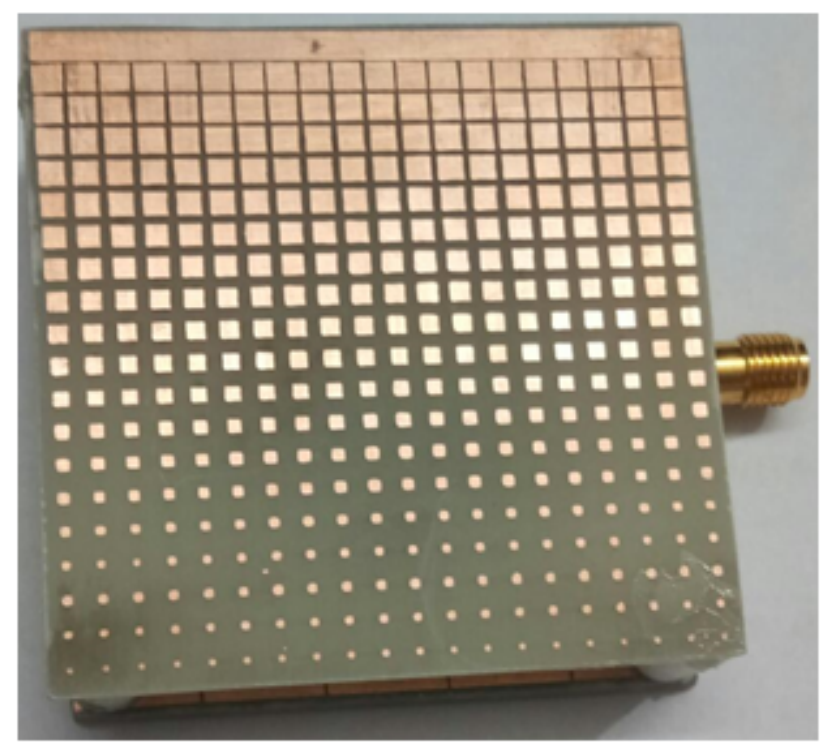

(a)

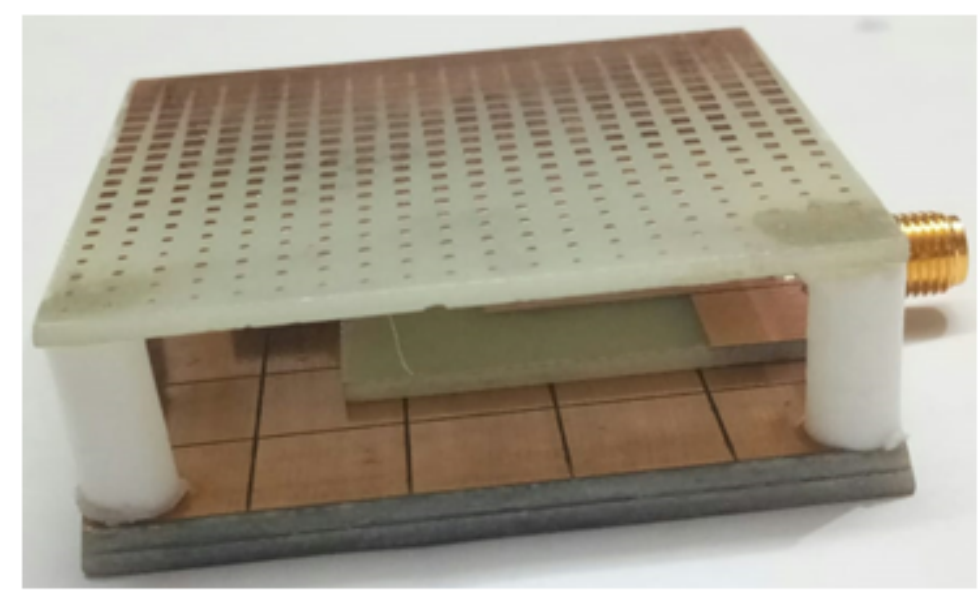

(b)

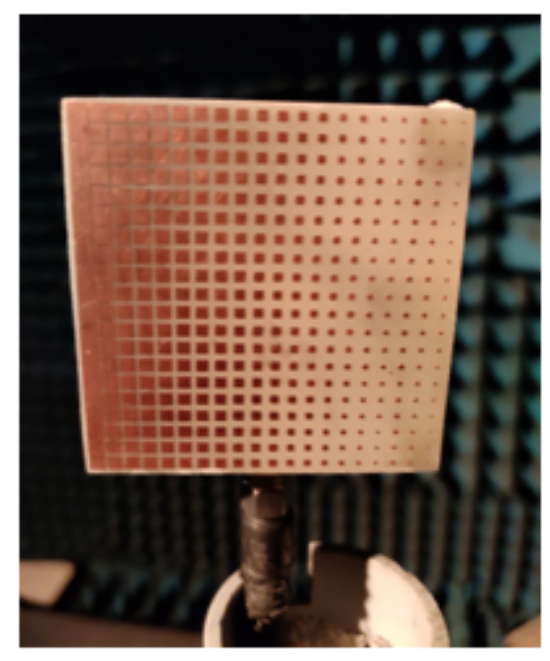

(c)

Figure 5

Prototype of the proposed CPW fed antenna with AMC and superstrate, (a) top view, (b) side view, (c) antenna in an anechoic chamber for measurement. 


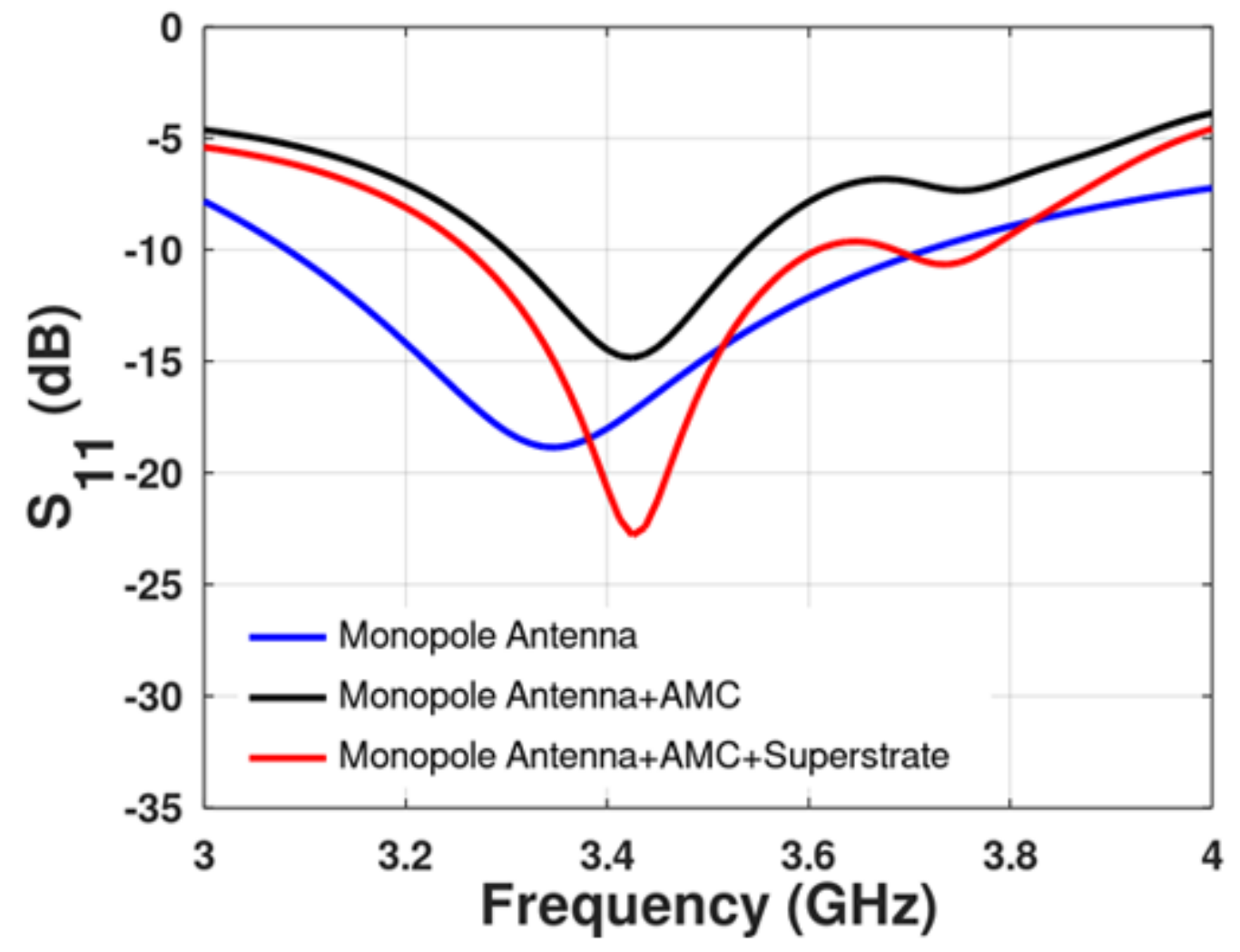

Figure 6

S-parameter comparison of the monopole antenna with AMC and superstrate.

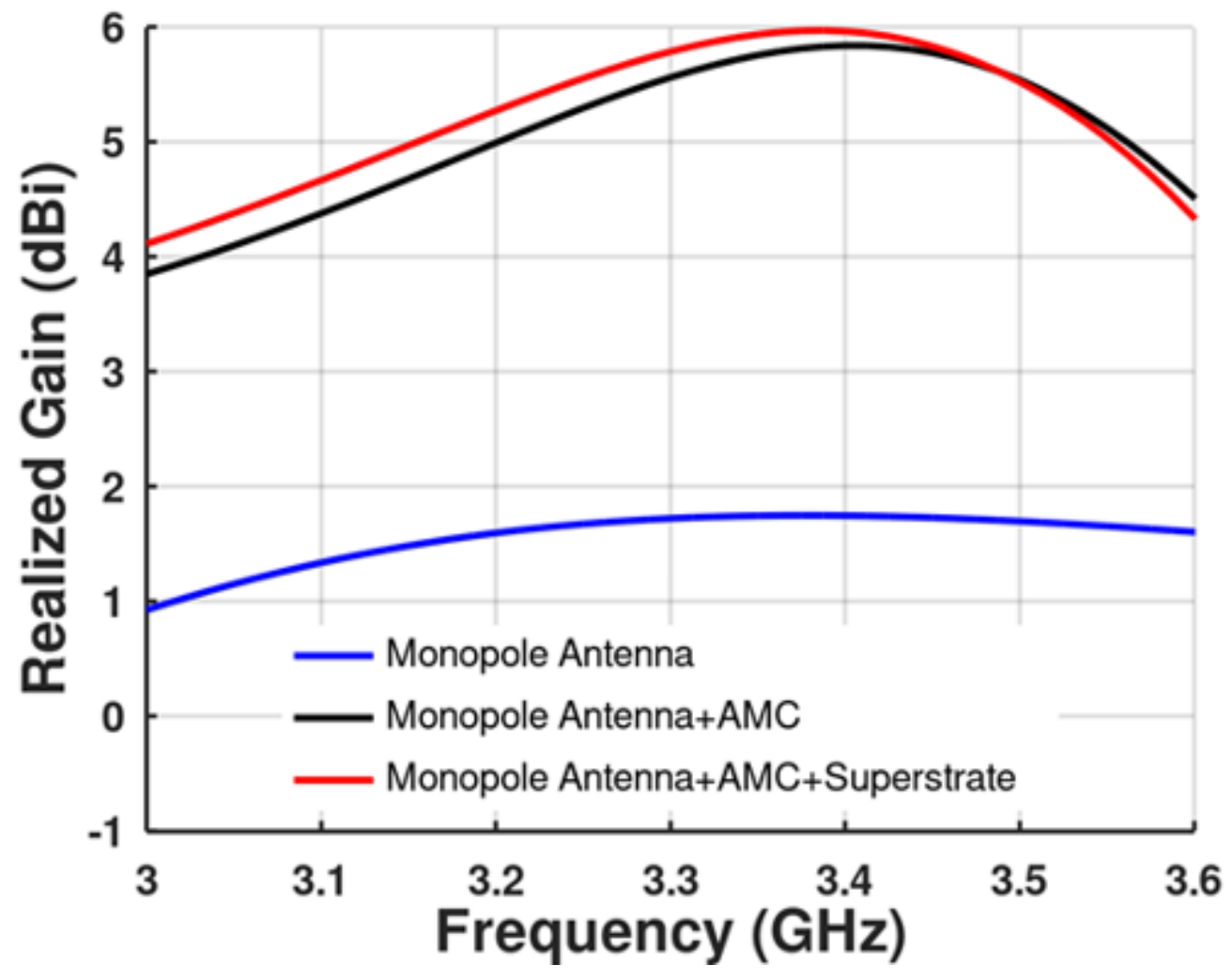

Figure 7 
Realized gain comparison of the monopole antenna with AMC and superstrate.

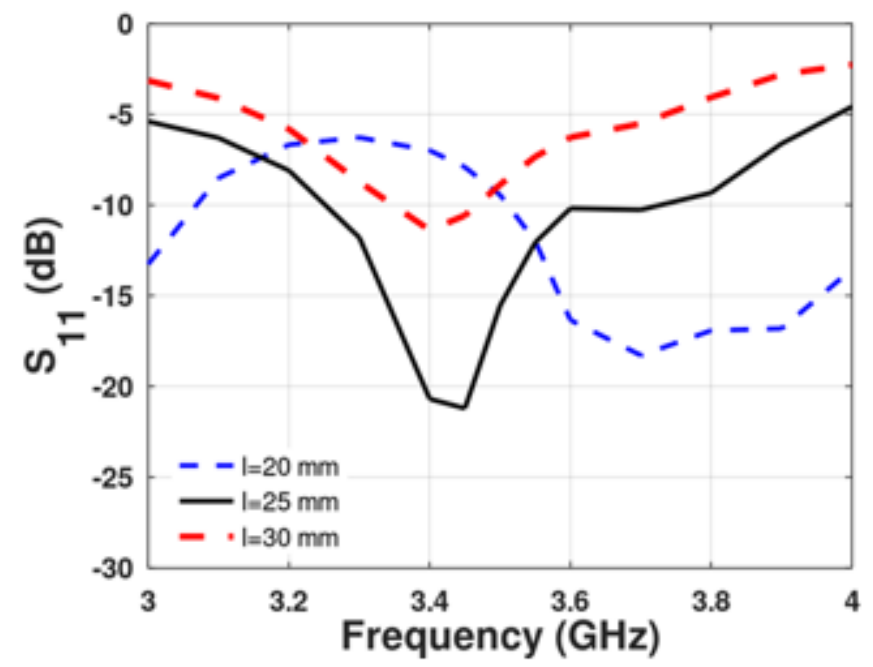

(a)

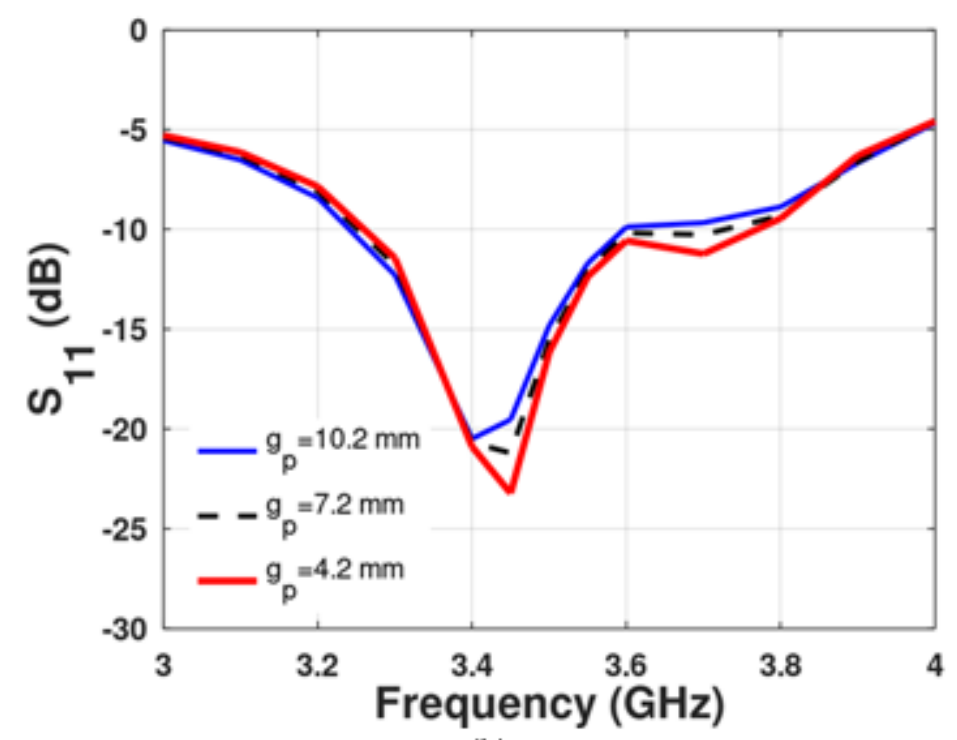

(b)

Figure 8

Parametric analysis of the antenna using: (a) monopole antenna length 'l'; (b) gap between antenna and superstrate 'g_p'. 


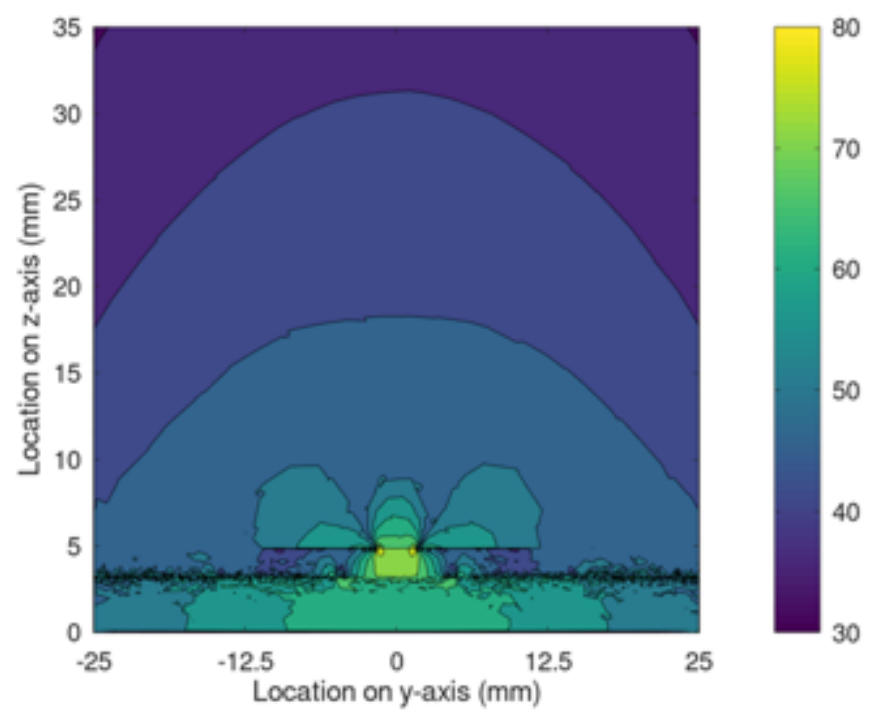

(a)

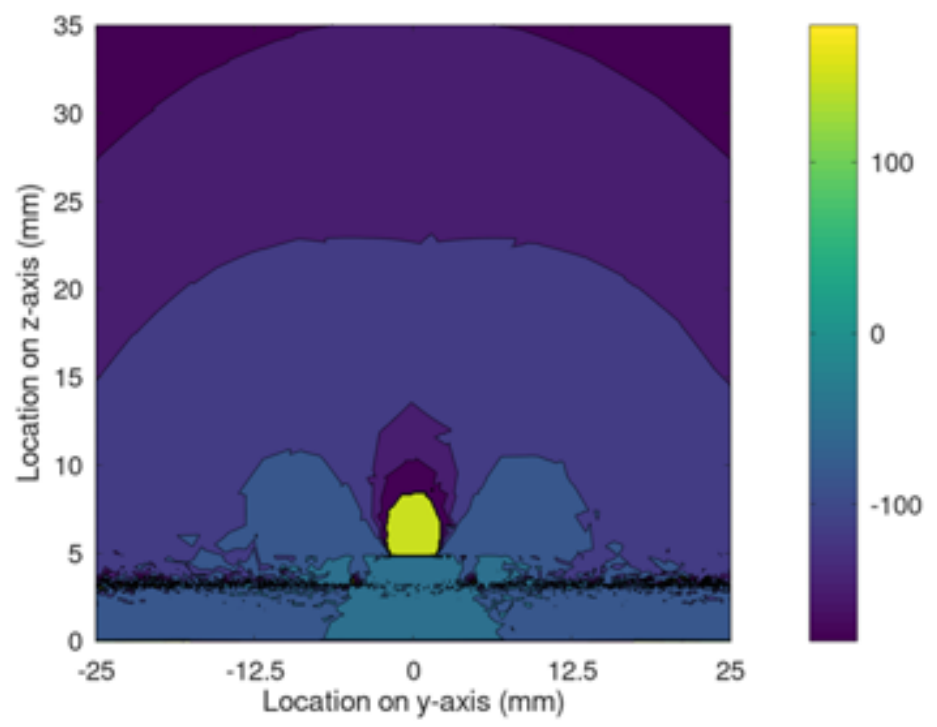

(b)

\section{Figure 9}

Near field performance of the antenna in absence of superstrate (a) E-field magnitude on a plane, (b) Efield phase on a plane. 

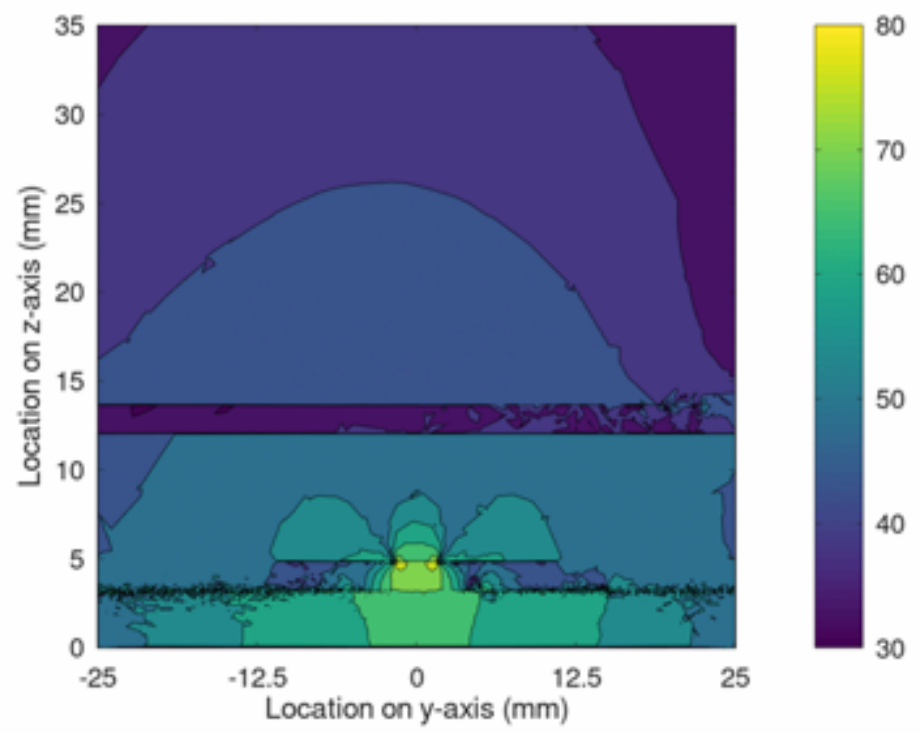

(a)

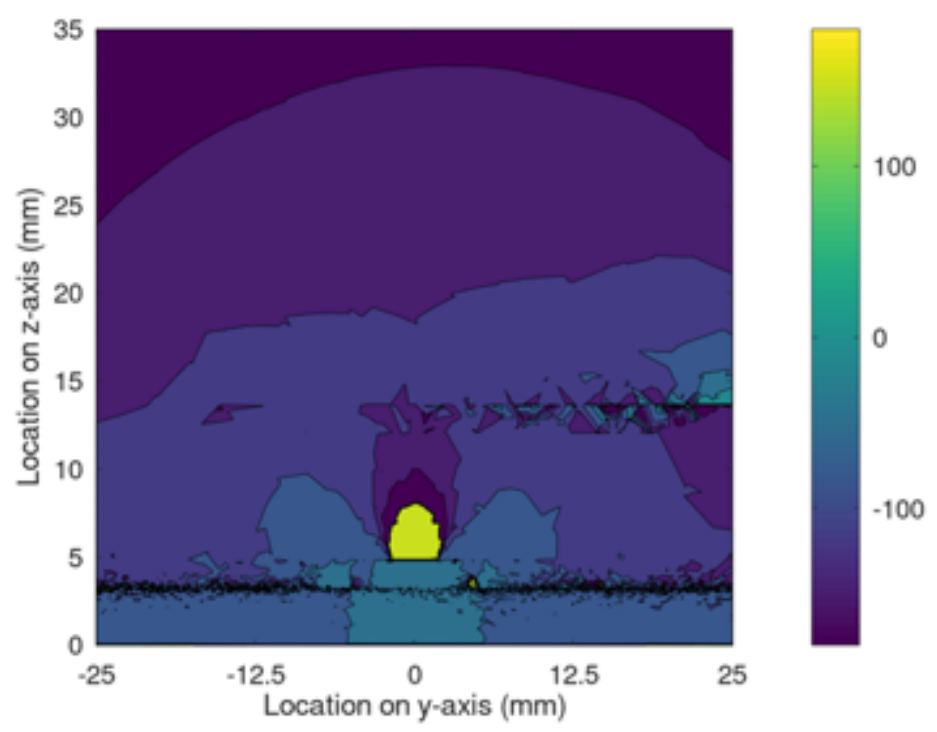

(b)

Figure 10

Near field performance of the antenna with superstrate (a) E-field magnitude on a plane, (b) E-field phase on a plane 


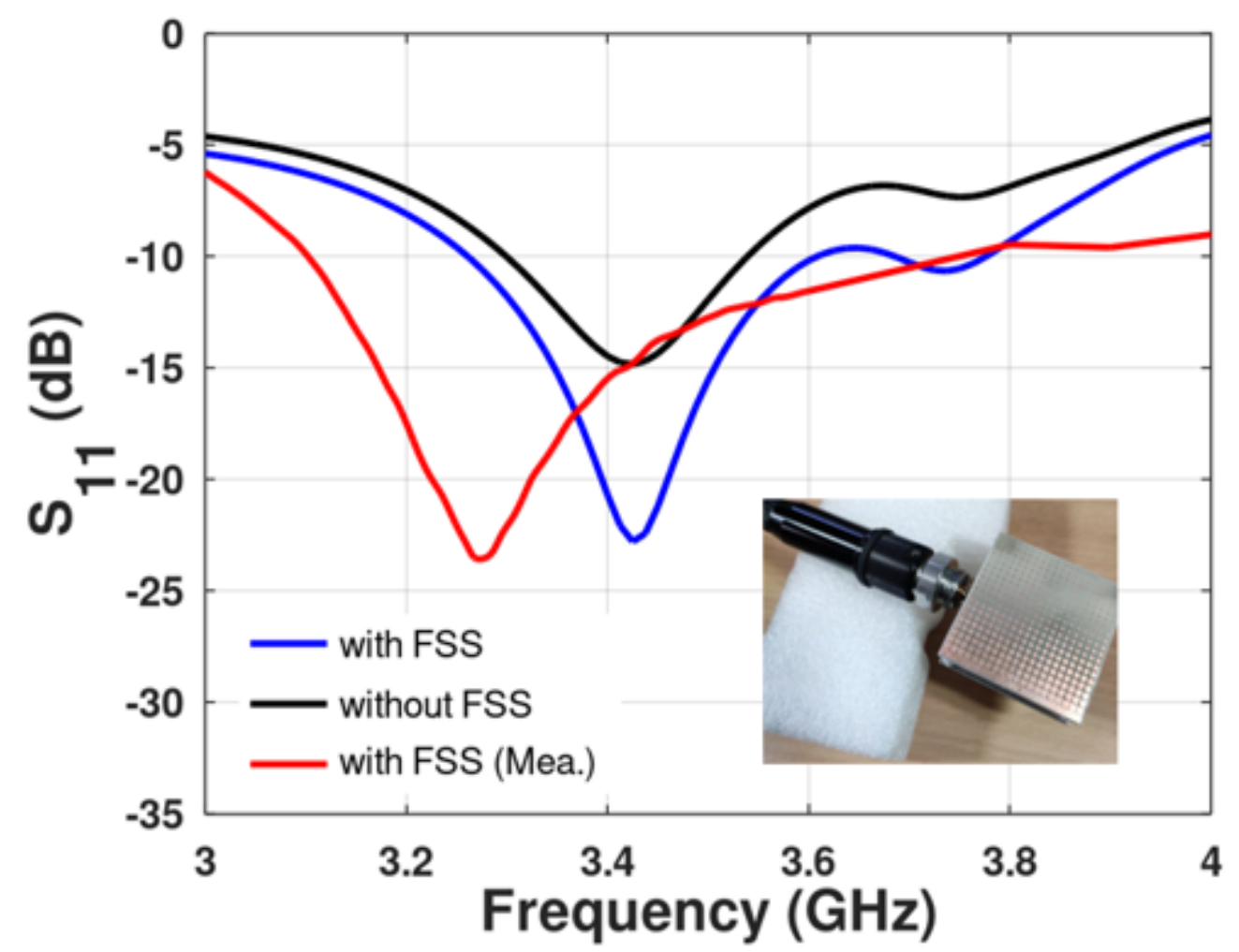

Figure 11

Measured and simulated S_11 of the proposed antenna.

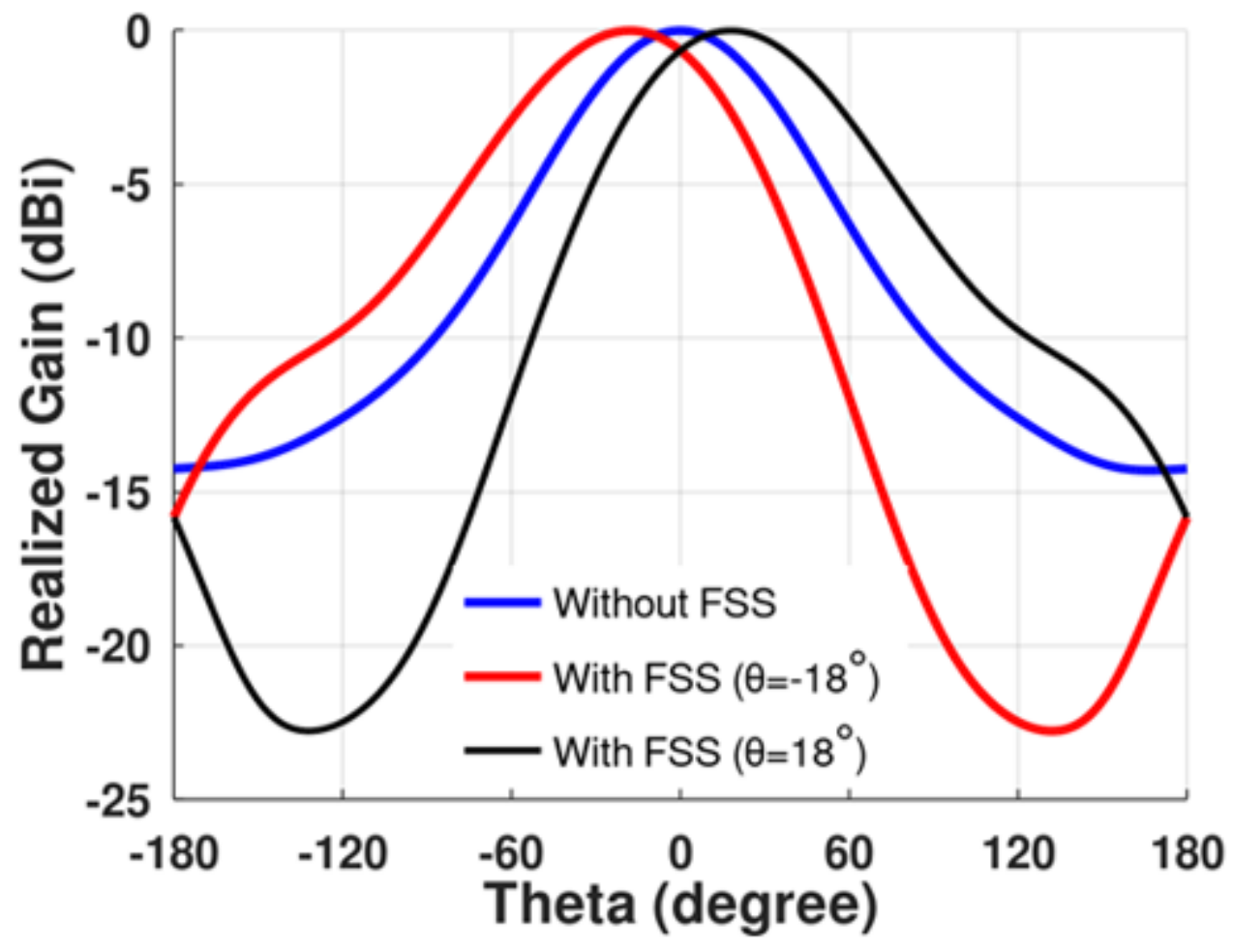

Figure 12

Radiation pattern in absence and presence of superstrate. 


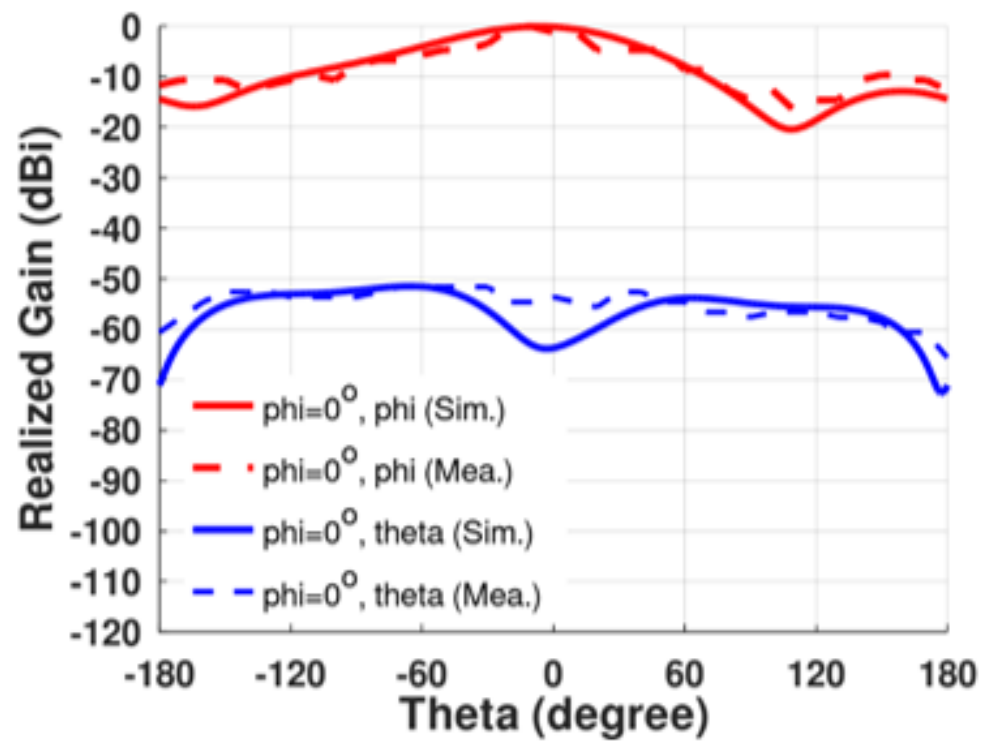

(a)

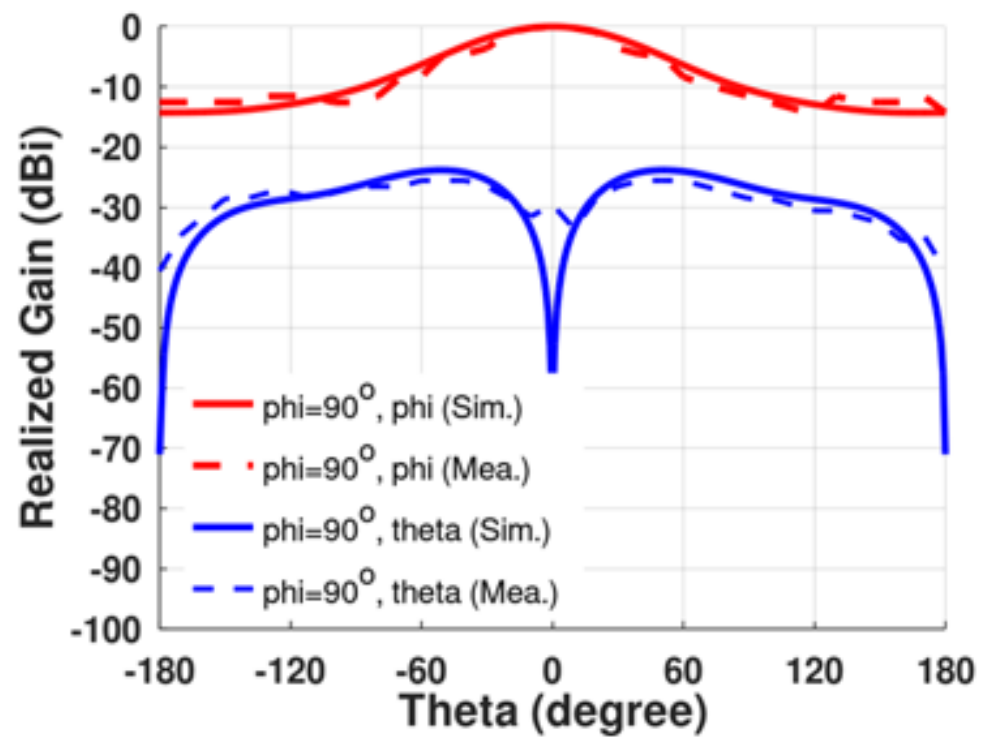

(b)

Figure 13

Simulated and measured radiation pattern of the antenna without superstrate, (a) $\varphi=0^{\circ}$ cut (b) $\varphi=90^{\circ}$ cut. 


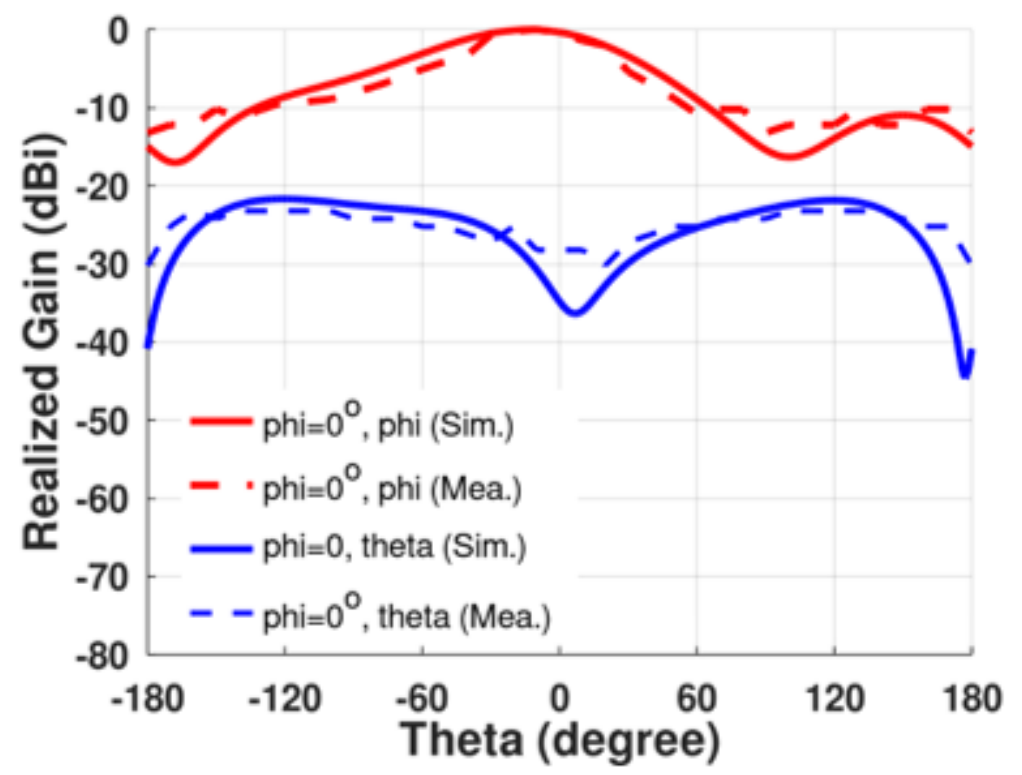

(a)

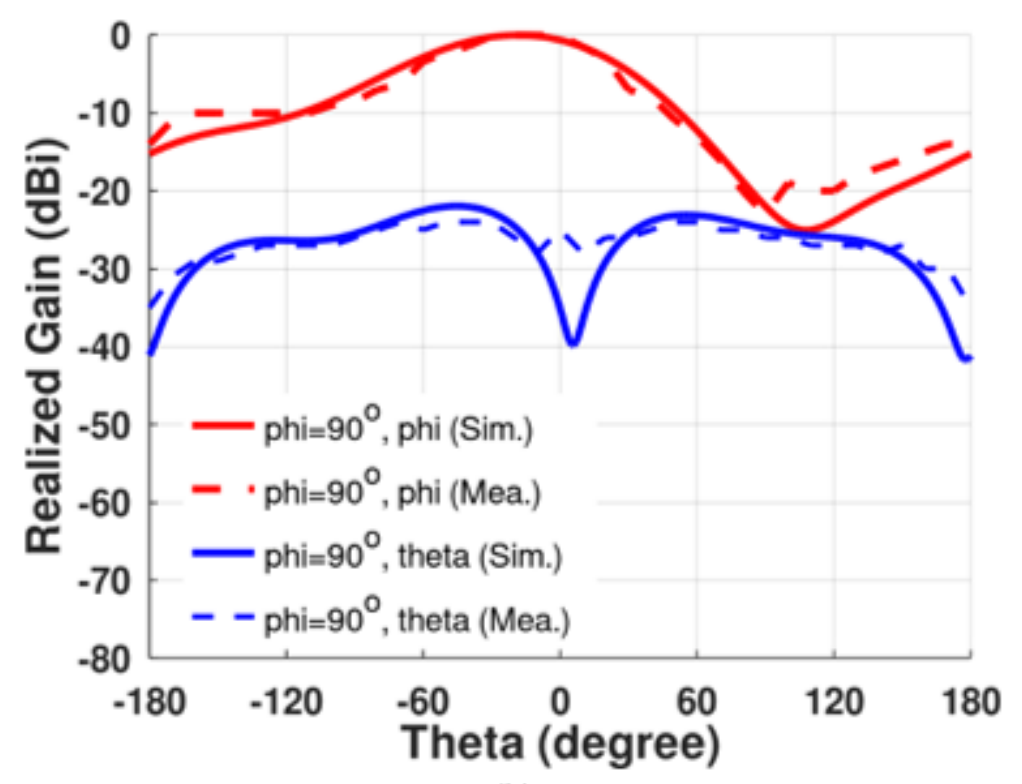

(b)

Figure 14

Simulated and measured radiation pattern of the antenna with superstrate, (a) $\varphi=0^{\circ}$ cut (b) $\varphi=90^{\circ}$ cut. 


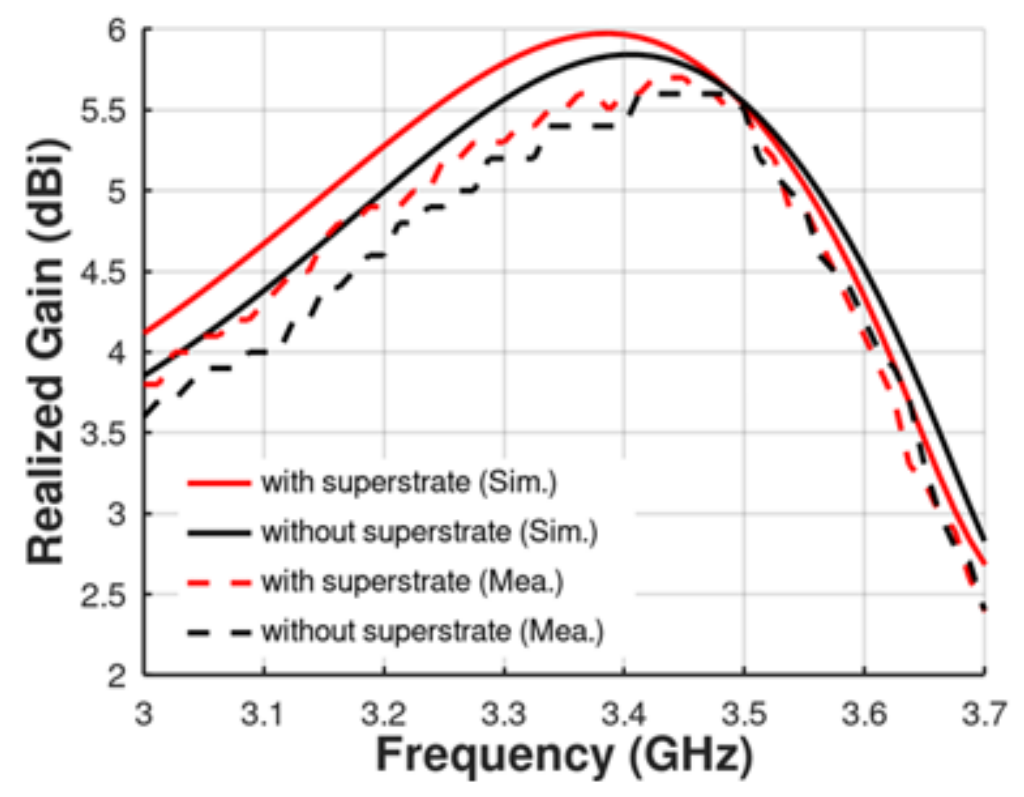

Figure 15

Peak realized gain of the antenna when the beam is steered in different directions. 